\title{
Comparative study to identify the safety, effectiveness and ease of obstetric forceps for delivery of floating head in cesarean section
}

\author{
Sonali Jitendra Ingole*, Saloni Manwani
}

Department of Obstetrics and Gynecology, Smt Kashibai Navale Medical College, Pune, Maharashtra, India

Received: 02 April 2018

Accepted: 14 April 2018

\section{*Correspondence:}

Dr. Sonali Jitendra Ingole,

E-mail: jitendra.ingole@gmail.com

Copyright: (C) the author(s), publisher and licensee Medip Academy. This is an open-access article distributed under the terms of the Creative Commons Attribution Non-Commercial License, which permits unrestricted non-commercial use, distribution, and reproduction in any medium, provided the original work is properly cited.

\begin{abstract}
Background: Difficulty is frequently encountered in extraction of floating fetal head. This study will focus on comparison of Forceps assisted fetal head extraction during Lower segment caesarean section (LSCS) with manual method of extraction in LSCS.

Methods: The ANC patients attending antenatal OPD and admitted for elective caesarean section fulfilling the inclusion criteria were randomly divided into two groups each of 400 patients: Group 1 of patients undergoing manual extraction of fetal head during LSCS; and Group 2 consisting of patients with forceps assisted delivery of fetal head in LSCS. Following factors will be evaluated in patients: maternal blood loss, any extension of uterine incision, difference in pre and post op hemoglobin levels of the patient and Apgar score of baby at 1 and 5 minutes.

Results: Patients in both the groups were matched demographically. The demographic variables such as maternal age, weight, parity and MGA (Mean Gestational age) were comparable in both the groups. Blood loss was significant in Group 1 (manual delivery) as compared with Forceps assisted delivery. This is also reflected in difference in pre and post op Hemoglobin levels. Although baby outcome in terms of Apgar score was similar in both groups, however morbidity in terms of uterine artery trauma, extension of uterine incision was much less in group 2 (Forceps assisted LSCS delivery)

Conclusions: Although there was no statistically significant difference in outcome of babies (APGAR score), complication(s) were less (blood loss, uterine artery trauma) in Forceps assisted LSCS delivery group. Proper selection of patient(s), early anticipation for application for Forceps can help for better outcome of caesarean delivery.
\end{abstract}

Keywords: Cesarean section, Delivery, Forceps

\section{INTRODUCTION}

The rate of cesarean section has increased dramatically all over the world over the past few years. ${ }^{1}$ In India, cesarean section rates have generally exceeded $30 \%$ of total deliveries. ${ }^{2}$ Public health efforts to optimize and decrease Caesarean section rates have not yielded results due to variety of factors. ${ }^{3,4}$

Many caesarean section are performed as repeat caesarean section in patients who have underwent lower segment caesarean section (LSCS) in previous pregnancy. Other common indications for elective LSCS are floating head at term, macrosomia, elderly primigravida, and maternal request.

Difficulty is encountered during delivery of head in some cases especially where head is high floating, lower segment is not well formed. Some of the methods which can be used to deliver fetal head in such cases are manual delivery using fundal pressure, lateral vertical incision ( $\mathbf{J}$ incision), inverted $\mathrm{T}$ incision, or application of ventouse 
and forceps. ${ }^{5,6}$ Delivery of floating head by application of forceps during Caesarean section is safe and effective alternative to manual delivery with fundal pressure.

\section{Potential advantages of using forceps}

- Ability to decrease the amount of fundal pressure required for delivery

- Avoidance of dependence on the assistant

- Help in guiding the fetal head through the uterine incisiom when the lower segment is not well formed.

- Ability to avoid deliberate extention of uterine incision

- It is not subjected to pop off and can also be used to deliver preterms a potential advantage over ventouse

- Application of forceps depends only on the skill of the surgeon and can be done in low resource settings.

Objective of this study was to identify the safety, effectiveness and ease of obstetric forceps for delivery of floating head in cesarean section.

\section{METHODS}

\section{Inclusion criteria}

- Primigravida with cephalopelvic disproportion

- Women with previous lower segment caesarean section with head floating at term

- Vertex presentations in preterm patients with floating head requiring caesarean section for obstetric indications.

\section{Exclusion criteria}

- Deeply engaged fetal head

- LSCS in second stage of labor

- Non-vertex presentations

- Patients who opted out of trial.

This was a prospective, randomized case control study, conducted in Department of Obstetrics and Gynecology at Smt. Kashibai Navale Medical College and Hospital after obtaining approval from Ethical committee. This study was conducted from Dec 2015 to Dec 2017 over a period of 24 months. The study included 800 antenatal patients admitted for elective cesarean section and having high floating fetal head at term.

These 800 patients were randomly divided in to two groups (after obtaining the required consent).

- Group 1 (400 cases): Patients in whom fetal head was delivered manually

- Group 2 (400 cases): Patients in whom fetal head was delivered using forceps.
All cesarean sections were performed under spinal anaesthesia. All deliveries were timed using stopwatch, the time was counted from the starting of rupture of membranes after full transection of lower uterine segment (amnitomy) till full delivery of fetal head. Baby was handed over to Pediatrician and Apgar score at 1 and 5 min was assessed. The babies were also assessed for any evidence of injuries due to forceps application. Maternal blood loss was estimated using mop count, suction and postoperative hemoglobin levels.

\section{Manual extraction of fetal head}

The lower uterine segment was transected in usual manner which involved incision on lower uterine segment followed by either digital extension of lower uterine segment or using scissors.

Fundal pressure involves assistant placing one or two hands on the uterine fundus and exerting downward force while the obstetrician directs the fetal head through uterine incision. After amniotomy, the surgeon's hand was introduced in the uterus, below the fetal head. The surgeons hand guided the fetal head through uterine incision. Fundal pressure was given by the assistant for accomplishing the delivery of fetal head. If delivery of fetal head was not accomplished after two attempts of manual delivery, then it was proceeded with delivery using forceps.

\section{Forceps assisted extraction of floating fetal in cesarean section}

Wrigleys outlet obstetric forceps were used in this study. These forceps are light weight, has sliding lock with good cephalic curve, fenestrations on handle facilitating firm grip made its use easy and comfortable for surgeons. ${ }^{7}$

After stretching of the lower uterine segment and performing amniotomy, the dominant hand of the surgeon was introduced below the fetal head and one of the Blades of forceps was slided between the fetal head and the hand of the obstetrician. Doyens retractor was removed, and dominant hand of the surgeon was also removed. The blade was held in position by the assistant. Second blade of the forceps was placed between the fetal head and upper edge of the uterine incision.

Both the blades of forceps were locked with each other. Correct position of the blades was checked by making sure that the sagittal suture was oriented transversely between the two blades. Continuous steady traction was applied guiding the fetal head through uterine incision. After the delivery of the fetal head the blades were unlocked and handed over to the staff nurse and delivery of rest of the baby was done in usual manner of lateral flexion of the trunk. Failure to deliver fetal head using forceps was defined as inability to deliver fetal head after single pull or slippage of forceps. 
Technique of delivery of fetal head in both the groups, amnitomy to fetal head delivery interval, blood loss was estimated. Presence of any complications like postpartum hemorrhage, any extension of uterine incision and need for blood transfusion were noted.

The neonate was handed over to Pediatrician and following fetal parameters were assessed: Fetal birth weight, Any fetal injuries and Apgar score at 1 and 5 minutes.

\section{Statistical analysis}

The data collected was analysed using Stata software. It included chi-square test for categorical variables. A pvalue of $<0.05$ was considered statistically significant.

\section{RESULTS}

Patients in both the groups were matched demographically. The demographic variables such as maternal age, weight, parity and MGA (mean gestational age) were comparable in both the groups (i.e. observed $p$ value is not significant and is >0.05). Fundal pressure was required in all cases of manual extraction group. Only 13 patients in forceps group required additional fundal pressure. In the forceps group 394 out of 400 cases were successfully delivered by use of forceps application. Remaining 6 were delivered by manual method after failed forceps application.

Table 1: Comparison of demographic variables.

\begin{tabular}{|llll|}
\hline Variables & $\begin{array}{l}\text { Group 1 } \\
\text { (manual) }\end{array}$ & $\begin{array}{l}\text { Group 2 } \\
\text { (forceps) }\end{array}$ & $\begin{array}{l}\text { p } \\
\text { value }\end{array}$ \\
\hline Maternal age (year) & $24.4 \pm 4.7$ & $25.2 \pm 3.6$ & 0.91 \\
\hline Maternal weight $(\mathrm{kg})$ & $59 \pm 4.8$ & $61 \pm 3.7$ & 0.89 \\
\hline $\begin{array}{l}\text { Parity } \\
\begin{array}{l}\text { Mean gestational age at } \\
\text { the time of delivery } \\
\text { (weeks) }\end{array}\end{array}$ & 1.6 & 1.8 & 0.87 \\
\hline Fetal birth weight $(\mathrm{kg})$ & $2.93 \pm 0.86$ & $3.07 \pm 0.04$ & 0.88 \\
\hline
\end{tabular}

The cause of failure in 6 cases was due to incorrect application $(n=4)$, slippage of forceps $(n=2)$ while applying traction to fetal head.

In manual method, 337 out of 400 cases were delivered successfully by manual method. Fundal pressure was required in all cases of the manual group. There were 63 cases where the fetal head could not be delivered manually and were successfully delivered using forceps. Reasons for inability to deliver the head manually were incisional dystocia, deflexed head, oligohydramnios.

Table 2: Comparison based on clinical parameters.

\begin{tabular}{|c|c|c|c|c|}
\hline \multirow{2}{*}{\multicolumn{2}{|c|}{ Estimated blood loss (mL) }} & Group 1 (manual) $n=400$ & Group 2 (forceps) $n=400$ & p value \\
\hline & & 500 & 300 & 0.012 \\
\hline \multicolumn{2}{|c|}{$\begin{array}{l}\text { Difference in pre and post op hemoglobin } \\
\text { levels }(\mathrm{gm} / \mathrm{dL})\end{array}$} & 1.87 & 1.03 & 0.011 \\
\hline \multirow{2}{*}{$\begin{array}{l}\text { APGAR score of } \\
\text { neonate }\end{array}$} & 1 minute & 7 & 7 & 1.0 \\
\hline & 5 minutes & 8 & 8 & 1.0 \\
\hline \multicolumn{2}{|c|}{ Extension of uterine incision } & $7.75 \%(\mathrm{n}=31)$ & $2 \%(\mathrm{n}=8)$ & 0.0015 \\
\hline \multicolumn{2}{|c|}{ Trauma to uterine artery } & $5.5 \%(n=22)$ & $0.75 \%(\mathrm{n}=3)$ & 0.0013 \\
\hline \multicolumn{2}{|c|}{ Muscle cutting } & $10.5 \%(n=42)$ & $2.2 \%(n=9)$ & 0.002 \\
\hline
\end{tabular}

Blood loss was significant in Group 1 (manual delivery) as compared with forceps assisted delivery. This is also reflected in difference in pre and post op Hemoglobin levels. Although baby outcome in terms of Apgar score was similar in both groups, however morbidity in terms of unterine artery trauma, extension of uterine incision wasa much less in group 2 (Forceps assisted LSCS delivery).

\section{DISCUSSION}

The use of forceps during caesarean was first quoted by Sison HA. In another study by Warenski JC in his article described the use of Keilland forceps for assisted delivery of fetal head. ${ }^{9}$
One of the published studies, Bofil(2000) reported no difference between mean fall of hemoglobin in the groups comparing forceps and manual extraction. Also, there was no difference between extensions of uterine incision in both the groups. ${ }^{10}$ Although difficulty in delivery of fetal head at caesarean section has been encountered by many, few have reported the use of instrumental delivery. Difficult fetal extraction occurs in $1-2 \%$ of cesarean deliveries ${ }^{11}$ Review of published literature do not cite many studies describing the use of forceps during caesarean section, various meta-analysis and RCTs have quoted the effectiveness of use of ventouse during caesarean delivery. ${ }^{13}$

Application of ventouse requires training and is resource dependent (electricity, suction machine). Application of 
forceps on the other hand is a technique that can be easily performed even by postgraduate residents. In the present study, we found that the baby outcome (measured as Apgar Score) did not differ statistically in both the groups. However, Forceps application carries advantage in terms of less blood loss, lesser chances of extension of uterine incision and decreased trauma to uterine artery (Table 2).

Present study is comparable to similar study conducted by Swain et al in which they compared extraction of fetal head in 3 groups manual extraction forceps and ventouse. They found the U-D interval in the manual extraction group as $90.56 \pm 4.91$ seconds, in the forceps extraction group as $70.2 \pm 5.02$ seconds and in the Vacuum extraction group it was $62.3 \pm 2.03$ seconds. The difference in U-D interval was significant $(\mathrm{P}=0.04)$ between manual extraction and forceps extraction groups. There was significant $(\mathrm{P}=0.01)$ difference in $\mathrm{U}-\mathrm{D}$ interval between Manual and Vacuum extraction groups. No significant $(\mathrm{P}=0.22)$ difference was observed in the U-D interval between the forceps and vacuum extraction groups. ${ }^{13}$ Utilization of forceps is effective technique to assist delivery of fetal head during cesarean section. Less force and less traction time required by forceps extraction of head in LSCS as compared to Operative instrumental vaginal delivery minimizing the maternal and fetal complications as occur in vaginal instrumental delivery. To minimize the risk of uterine extension of incision, proper application of forceps and surgeon expertise remains essential.

In addition, at the time of elective caesarean section, the lower uterine segment is commonly not effaced or elongated, making it difficult to create an adequate incision to enable an uncomplicated delivery. Apart from this at the time of elective section fetal head is normally not deeply engaged in pelvis making manual extraction even difficult.

In patients with obesity or morbid obesity or big size baby, difficulty is frequently encountered to deliver fetal head manually. In such cases, application of forceps can help to reduce morbidity, blood loss considerably. Proper selection of patient(s), early anticipation for application for Forceps can help for better outcome of caesarean delivery.

\section{CONCLUSION}

Although there was no statistically significant difference in outcome of babies (APGAR score), complication(s) were less (blood loss, uterine artery trauma) in Forceps assisted LSCS delivery group. Proper selection of patient(s), early anticipation for application for Forceps can help for better outcome of caesarean delivery.
Funding: No funding sources Conflict of interest: None declared

Ethical approval: The study was approved by the Institutional Ethics Committee

\section{REFERENCES}

1. Declercq E, Young R, Cabral H, Ecker J. Is a rising cesarean delivery rate inevitable? Trends in industrialized countries, 1987 to 2007. Birth. 2011;38(2):99-104

2. Sritippayawan S, Chantrapitak W. Assisted delivery of high floating fetal head: a comparison of vacuumassisted delivery with manual extraction. Asian Biomed. 2011;5:699-703.

3. Khurshid N, Sadiq F. Management of primigravida with unengaged head at term. PJMHS. 2012;6(1):36-9.

4. Neuman M, Alcock G, Azad K, Kuddus A, Osrin D, More NS, et al. Prevalence and determinants of caesarean section in private and public health facilities in underserved South Asian communities: crosssectional analysis of data from Bangladesh, India and Nepal. BMJ open. 2014;4(12):e005982.

5. Hoogsteder PH, Pijnenborg JM. Use of uterine fundal pressure maneuver at vaginal delivery and risk of severe perineal laceration. Arch Gynecol Obstet. 2010;281(3):579-80.

6. Nakano R. Use of the vacuum extractor for delivery of the fetal head at cesarean section. Am J Obstet Gynecol. 1981;141(4):475-6.

7. Shashank S, Neena R, Singh JR. A prospective randomized study comparing maternal and fetal effects of forceps delivery and vacuum extraction. J Obstet Gynecol India. 2013;63(2):116-9.

8. Warenski JC. A technique to facilitate delivery of the high-floating head at cesarean section. American journal of obstetrics and gynecology. 1981;139(6):6257.

9. Bofill JA, Lencki SG, Barhan S, Ezenagu LC. Instrumental delivery of the fetal head at the time of elective repeat cesarean: a randomized pilot study. Am J Perinatol. 2000;17(5):265-9.

10. Levy R, Chernomoretz T, Appleman Z. Head pushing versus reverse breech extraction in cases of impacted fetal head during cesarean section. Eur J Obstet Gynecol Reprod Biol. 2005;12:24.

11. Waterfall H, Grivell RM, Dodd JM. Techniques for assisting difficult delivery at caesarean section. Cochrane Database Syst Rev. 2016;1:CD004944.

12. Sujata S, Sagarika N, Satpathy RN, Purna M. Assisted delivery of mobile fetal head: a comparison of forceps, vaccum and assisted manual extraction of head at caesarean section. Int J Reprod Contracept Obstet Gynecol. 2017;6(9):4065-70.

Cite this article as: Ingole SJ, Manwani S.

Comparative study to identify the safety,

effectiveness and ease of obstetric forceps for

delivery of floating head in cesarean section. Int $\mathbf{J}$

Reprod Contracept Obstet Gynecol 2018;7:1760-3. 